the sole sponging necessary being the use of one sterile swab for each tonsil fossa. There is no sickness, and the careful examination of the fossa, which is so essential, is made quite easy. The total absence of congestion makes this method ideal for such cases as pericarditis and exophthalmic goitre, and any of those chronic infective conditions which so frequently need tonsillectomy. Many such cases are included in my list, and the contrast has been very striking when compared to other methods.

The apparatus was designed by Dr. Yankauer, of New York. I am, Sir, yours faithfully,

Welbeck-street, W., Feb. 23rd, 1920.

\section{THE LESSONS OF STATISTICAL METHODS.}

To the Editor of THE LANCET.

SIR,-Dr. H. Batty Shaw's lecture in THE LANCET of Jan. 24th on Pulmonary and Other Forms of Tuberculosis has brought to my mind a subject which I have thought a good deal about and which I may call the statistical evaluation of different lines of treatment in disease. I am not acquainted with any work, either of a private or official nature, which effects this-a most important subject for all who have to advise patients on the probable best line of treatment to adopt.

I can make clear what I mean, I think, by a hypothetical case of any common disease. A patient consults me with, say, cancer of the breast involving the axillary glands, and I, as a general practitioner, get a surgeon's advice and he advises an operation. I recommend my patient to follow the surgeon's advice, but at the same time am not quite sure in my mind that the result will be a satisfactory one. But what am I to do? All the surgeons say that the evidence is overwhelming for operative measures; but where can I get evidence of, say, 5000 operations for breast cancer and the duration of life, freedom from pain, absence of recurrence and for how long, and so forth? Can I get evidence of 5000 breast cancers treated by any one other method and their results?

The essence of this idea lies in the following up of all cases of illness, however trivial, and the treatment adopted over a considerable number of years; in fact, it means a medical history-sheet for every member of the community, which would ultimately have to be classified, and a group formed for a period of five years or more or less, from which one would get some idea as to some outstanding therapeutic measure of any real value.

What are therapeutics at the present day? Frequently individual fancies of the practitioner based on his own, necessarily very small, experience, and the statements, also usually the experiences of an individual, that he reads in books on therapeutics. We should all like to be able to get statistical evidence of say 100,000 cases of tuberculosis, which would go far to convince us that the tuberculosis of the adult was an "inside" infection from an old arrested infection of chilchood, or that it was an "outside," say inhalation, infection, from an infected dwelling, as it would make an enormous difference to our methods of combating the disease.

I once was discussing some operative procedure with a friend who had been a house surgeon in a large clinical hospital and left this appointment with all the enthusiasm of youth for this operative procedure, but his enthusiasm was sadly damped by a period of residence in a workhouse infirmary in the neighbourhood shortly after when he saw several of these surgical triumphs coming in to die. Here we have individual experience of the smallest degree, but it is going to influence that practitioner in his future practice. Would it not be an enormous advantage if a thousand or ten thousand cases of that disease, their duration, and general course under the operation in question and alternative methods were available at a central clearing-house where the practitioner could get information from.

It will naturally be asked how is this colossal amount of information to be obtained. The present National
Insurance system is a ready-made channel for working through, and with regard to that system I am of opinion that a large amount of the trivial work performed by the general practitioner could be performed by nurses, and a reduced quantity of a better-class and betterpaid-for work conld then be performed by the practitioner.

It is, perhaps, pointing to all medical service being a question of State service, but whether that be so or not I am quite convinced that it is only by the comparative valuation of therapentic measures taken in as large a number of cases as possible and their results watched and estimated over as long a period as possible, that we shall emerge from, shall I say, the empiricism of the physician and the individualism of the surgeon.

I am, Sir, yours faithfully,

Charing, Kent, Feb. 14th, 1920. H. E. LITTLEDALE, M.D.

\section{THE DIAGNOSIS OF MALARIA.}

\section{To the Editor of THE LANCET.}

SIR,--In the Experiences of Malaria in the Egyptian Expeditionary Force published in THE LANCET of Jan. 10th Mr. Philip Manson-Bahr rightly insists on the necessity of early microscopic diagnosis in malaria. The reason given is that in its absence clinicians are liable to make mistakes. Three cases diagnosed clinically as sunstroke were subsequently found, by microscopic examination, to have been malignant malaria; five cases of dysentery were subsequently diagnosed malarial enteritis ; cases diagnosed clinically as relapsing and enteric fevers were subsequently, by microscopic diagnosis, found to have been malarial relapses; and cases diagnosed clinically as epidemic influenza, which was prevalent, were subsequently diagnosed by microscopic examination as malignant malaria. The small number of clinical mistakes discovered in the sick of such a large force reflects, I think, sreat credit on the medical officers of the force. Such mistakes are not always avoidable under the circumstances attending a rapid advance of a large force in the field.

In Palestine malarial fever is very prevalent. Masterman, who investigated malaria there before the war, remarked that the verdict of the microscope upsets all ideas of clinical experience. Parasites are found swarming in the blood of some, especially children, who exhibit no rise of body temperature, and who are to all appearance in good health, whilst in others suffering from what is clinically a typical malarial fever not even one parasite can be found in the blood. Hence it is possible that the subsequent discovery of parasites in a patient's blood does not mean that the original clinical diagnosis of another disease must necessarily have been an error. Also the failure to find parasites in the blood during the first few days of a primary attack of malaria does not exclude the possibility of the disease being malaria. The absence of parasites from the blood during the first three days of the fever is well illustrated in the original report of Manson's famous experiment in London, as published in THE LANCET of Sept. 29th, 1900, p. 923. Mosquitoes fed on malarial subjects in Rome had been brought to London and there allowed to bite two healthy young men. Of the two bitten men, the history of only one is related in the report. He had been bitten by about 55 mosquitoes on the hands and arms. This produced considerable irritation of the skin, persisting for two days, and subsequently malarial fever developed. During the first three days of the fever the body temperature varied between $100^{\circ} 4^{\circ}$ and $103 \cdot 6^{\circ} \mathrm{F}$., but not even one parasite could be found in the blood, although repeatedly searched for. On the morning of the fourth day of the fever body tem. perature had fallen to $98^{\circ} 4^{\circ}$, and rose again to $102^{\circ} 8^{\circ}$. Repeated microscopic examination of the blood revealed only one doubtinl half-grown tertian parasite. On the fifth day of the fever the morning body temperature was $99^{\circ}$. Several half-grown parasites, one gamete, and two pigmented leucocytes were found in the blood in the first film examined. During the day many tertian parasites were found, and the body temperature rose to $103^{\circ}$. On the sixth day of the experiment 